\title{
INCIDENCE OF IMMUNOGLOBULINS IN FLUIDS OF THE RABBIT GENITAL TRACTS AND THE DISTRIBUTION OF IgG-GLOBULIN IN THE TISSUES OF THE FEMALE TRACT
}

\author{
D. B. A. SYMONS AND J. HERBERT \\ Agricultural Research Council, Institute of Animal Physiology, Babraham, \\ Cambridge
}

(Received 6th February 1970)

\begin{abstract}
Summary. The incidence of immunoglobulins in the fluids and tissues of rabbit genital tracts has been assessed by immuno-electrophoresis and immunofluorescence. Seminal plasma contained a variable quantity of IgG-globulin, ranging from undetectable amounts to concentrations comparable to that of blood serum, the incidence of which was random in serial ejaculates. IgG-globulin was present in follicular, uterine and vaginal fluids, IgA-globulin also occurring in some vaginal samples.

A proportion of spermatozoa recovered from the female tract $7 \mathrm{hr}$ post coitum had reacted with IgG of female origin.

The epithelium of the female tract at all levels prevented the diffusion of IgG from the relatively high levels in tissue fluid to the low levels in luminal fluid. IgG was found to be localized intercellularly in the epithelium, particularly in the vagina and the glandular epithelium of the pregnant uterus. It is inferred that IgG transfer into luminal fluids is by an intercellular route.
\end{abstract}

\section{INTRODUCTION}

The luminal fluids of the rabbit female genital tract contain a variety of proteins, some of which are specific for this organ, others being common to, and thus presumably derived from, blood plasma (Stevens, Hafs \& Hunter, 1964; Beier, 1968; Daniel, 1968). The plasma-derived proteins of the female tract fluids include the most prominent immunoglobulin class of plasma and body fluids, namely IgG- $(\gamma \mathrm{G}-)$ globulin, although present in a much lower concentration in tract fluids than in plasma. Uterine transmission of immunoglobulin is increased in the later stages of pregnancy when the rabbit foetus receives maternal immunoglobulins by maternal transfer to the uterine luminal fluids and hence by way of the yolk sac circulation to the foetus (Brambell, 1958). Uterine transmission in pregnancy includes both IgG-(7S) globulin and IgM-(19S) macroglobulin (Hemmings \& Jones, 1962). However, the manner of transfer of immunoglobulins across the uterine epithelium at any stage of the reproductive cycle has not been described. 
A major problem in any analysis of genital tract fluids is encountered in the recovery of sufficient quantities of uncontaminated or unaltered fluids (Heap, 1962; Edwards, 1969). Cannulation or ligation of the tract in order to enhance the fluid yield produces modification of the composition of uterine fluid. The present report describes the immuno-electrophoretic analysis for immunoglobulins of rabbit seminal plasma and vaginal, uterine and follicular fluid, the female fluids being those directly recoverable from the genital tract immediately post mortem. The route of transfer of IgG-globulin across the female genital tract epithelium has been assessed by immunofluorescence. This technique has also been used to test for interaction between spermatozoa and the IgGglobulin present in varying amounts in both male and female genital tract fluids, since it is in this class of immunoglobulin that natural antibodies to spermatozoa and testis cells occur in a variety of mammalian species (Edwards, 1960; Beck, Edwards \& Young, 1962; Spooner, 1964; Johnson, 1968). Previous tracing by immunofluorescence of rabbit globulin reacting with spermatozoa recovered from the female tract (Symons, 1967, 1968) was of wide spectrum compared with the present specific tracing of IgG-globulin.

\section{MATERIALS AND METHODS}

\section{Preparation of conjugated antibody}

Goat anti-rabbit $\operatorname{IgG}$ serum was prepared by multiple intramuscular injections over a 6-month period of DEAE-purified rabbit IgG, each dose consisting of $50 \mathrm{mg} \mathrm{IgG}$ as a $1 \%$ solution in Freund's adjuvant injected into four sites. Antiserum was fractionated on DEAE cellulose (Whatman, DE23) equilibrated with $0.0175 \mathrm{~m}$-phosphate buffer, $\mathrm{pH} \mathrm{6.5.} \mathrm{The} \mathrm{exclusion} \mathrm{peak} \mathrm{con-}$ taining IgG was retained for conjugation with fluorescein isothiocyanate (FITG). Conjugation was carried out in $0.2 \mathrm{M}$-phosphate buffer $\mathrm{pH} 9 \cdot 3$, adding $1 \mathrm{mg}$ FITC (BDH) to each $100 \mathrm{mg} \mathrm{IgG}$, for $1 \mathrm{hr}$ at room temperature and then overnight at $4^{\circ} \mathrm{C}$. Excess FITC was removed by passing the crude conjugate down a Sephadex G25 column, 0.01 m-phosphate, $\mathrm{pH} 7 \cdot 6$. The conjugate was then fractionated by stepwise chromatography on DEAE-cellulose (DE 23), the fractions having a fluorescein-protein molar ratio between 2 and 4 being used for immunofluorescence.

\section{Immunofluorescence}

Cross reaction of the anti-IgG conjugate with other antibody classes through the common immunoglobulin light chains was abolished by absorption with rabbit Fab fraction (Porter, 1959). The absorbed conjugate was specific for IgG; absorption with tissue powders was not therefore carried out. Any nonspecific reaction of the conjugate with tissue components was assessed by absorbing the conjugate with rabbit IgG, residual fluorescence of tissue sections then being attributed to non-specific binding of conjugate. Specificity was also checked by application of the 'blocking test' (Nairn, 1962).

Both the direct and indirect immunofluorescence methods were used. Tissue sections and preparations of spermatozoa recovered from the female tract were treated directly with anti-IgG conjugate. Ethanol-fixed preparations of 
ejaculated rabbit spermatozoa were first treated with serum or immunoglobulin solutions, washed and then treated with conjugate. Details of the fluorescence microscopy have previously been described (O’Donnell \& Symons, 1970).

\section{Preparation of tissue sections}

Oestrous rabbits were mated twice to fertile bucks and killed $7 \mathrm{hr}$ post coitum (p.c.) by intravenous injection of methohexitone (Brietal; Elanco Products Ltd). The genital tract was removed and small portions of uterus, cervix and vagina snap frozen in Arcton 12 (ICI) or isopentane cooled in liquid nitrogen. Tissues were freeze-dried at $-30^{\circ} \mathrm{C}$ under vacuum ( $₹ 0.001$ Torr) and vacuum embedded in $57^{\circ} \mathrm{C}$ melting-point paraffin wax. Sections cut at 6 to $8 \mu$ were floated out on xylol on microscope slides, dried, fixed in $95 \%$ ethanol and dried again.

\section{Recovery of luminal fluids and spermatozoa from the female tract}

Very few spermatozoa were found in freeze-dried sections of the female tract; these were usually reduced to a membrane-less, tail-less state, presumably as a result of the freeze-drying process. For this reason, a method was developed for the recovery of spermatozoa from the female which minimized the risk of contaminating the tract fluids with blood or tissue fluids. The tract was ligated at each utero-tubal junction and anterior to the urethral portion of the vagina before removal from the animal. The external surfaces were gently cleaned and the uterine horns and vagina opened by cautery on their ventral surfaces, entry being made between major blood vessels. The fluid contents were collected by capillarity into smooth-ended micro-haematocrit tubes, the cellular contents separated by centrifugation and the fluid portion retained for immuno-electrophoretic analysis. The cellular fractions (spermatozoa and polymorphonuclear leucocytes) were resuspended in buffered saline and ethanol-fixed preparations made on microscope slides.

\section{Immuno-electrophoresis}

A modification of the micro-method of Scheidegger (1955) was employed, as described by Pierce \& Feinstein (1965), using $1.5 \%$ (w/v) agar in $0.1 \%$ sodium azide and sodium barbitone buffer $\mathrm{pH} 8 \cdot 6, I=0 \cdot 025$.

\section{RESULTS}

Reaction of rabbit spermatozoa with homologous IgG-globulin from normal (nonimmune) serum

The IgG-globulin of normal homologous serum reacted moderately with the acrosomal region of ejaculated rabbit spermatozoa, as determined by anti-IgG immunofluorescence. Reaction of a $1 \%$ solution of immuno-electrophoretically pure IgG-globulin prepared by DEAE chromatography from non-immune serum reacted very intensely with the acrosome region of the spermatozoon (PI. 1, Fig. 3). It therefore appears that in the rabbit, as in the guinea-pig (Johnson, 1968), the activity against spermatozoa found in normal serum is contained principally in the IgG-globulin fraction. 
IgG-globulin in rabbit seminal plasma

Immuno-electrophoretic analysis of the fluid portion of rabbit seminal plasma collected by artificial vagina showed that the occurrence of IgGglobulin in this fluid was very variable, ranging from amounts undetectable in the immuno-electrophoretic method used (the minimum detectable concentration of IgG, determined from serial dilutions of serum and using the same indicator antiserum, was of the order of $0.005 \%$ ) to levels comparable to those found in serum (1\%) (Pl. 1, Fig. 1). The samples shown in Pl. 1, Fig. 1 were obtained at approximately 10-min intervals from a single buck. IgG appeared in the third ejaculate of the first series, being absent in the first two ejaculates, while in the second series IgG was present in the first ejaculate and absent from the three subsequent ejaculates. The presence of $\mathrm{IgG}$ in rabbit semen, therefore, appears to be variable and at random in serial ejaculates. Immunofluorescence of spermatozoa prepared from IgG-rich semen (Pl. 1, Fig. 1, No. 3) failed to demonstrate any reaction of seminal IgG with these spermatozoa, even after incubation for $1 \mathrm{hr}$ in this semen.

\section{IgG-globulin reaction with uterine and vaginal spermatozoa}

Spermatozoa recovered from the female tract $7 \mathrm{hr}$ p.c. were examined for reaction with IgG of female origin. A proportion of both vaginal and uterine spermatozoa (approximately $22 \%$ and $7 \%$ respectively) was found to fluoresce moderately when treated with IgG conjugate (Pl. 1, Figs. 4 and 5). Other cells could be found in each sample which exhibited weak fluorescence, while approximately $30 \%$ of uterine and $20 \%$ of vaginal spermatozoa were nonfluorescent.

Immunoglobulins in luminal fuids of the female genital tract and in follicular fluid

The amounts of luminal fluid freely recoverable from the uterus and vagina were small; 0.05 to $0.1 \mathrm{ml}$ from each uterine horn, and 0.1 to $0.2 \mathrm{ml}$ from the vagina. Vaginal fluid contaminated with urine was discarded. Follicular fluid was obtained by aspiration of the ripe follicle through a fine-gauge hypodermic needle. Plate 1, Fig. 2 shows the results of immuno-electrophoresis of these fluids. IgG-globulin was detected in all samples, although its concentration in

\section{EXPLANATION OF PLATE 1}

FIG. 1. Immuno-electrophoresis of rabbit seminal plasmas. AS = anti-rabbit serum; AG $=$ anti-rabbit IgG; $\mathrm{S}=$ rabbit serum. Nos. 1 to 3 represent first series of ejaculates taken at 10 -min intervals; 4 to 7 represent second series. AG is the serum used for FITC conjugation.

FIG. 2. Immuno-electrophoresis of female genital fluids. $S=$ rabbit serum; $F=$ follicular fluid; $\mathrm{U}=$ uterine fluid; $\mathrm{V}=$ vaginal fluid (taken from a different animal than the three other samples).

FIG. 3. Immunofluorescence of ejaculated rabbit spermatozoa treated with a $1 \%$ solution of rabbit IgG prepared from normal serum, followed by anti-IgG conjugate. Bright fluorescence of acrosome region, particularly over apical ridge. $(\times 670)$.

Fig. 4. Immunofluorescence of vaginal spermatozoa recovered $7 \mathrm{hr}$ p.c. Central spermatozoon shows acrosome fluorescence; others are in various stages of acrosome degeneration. $(\times 520)$.

Fig. 5. Immunofluorescence of uterine spermatozoon at $7 \mathrm{hr}$ p.c. Spermatozoon, with acrosome fluorescence, is adherent to a polymorphonuclear leucocyte. $(\times 520)$. 
11.11.
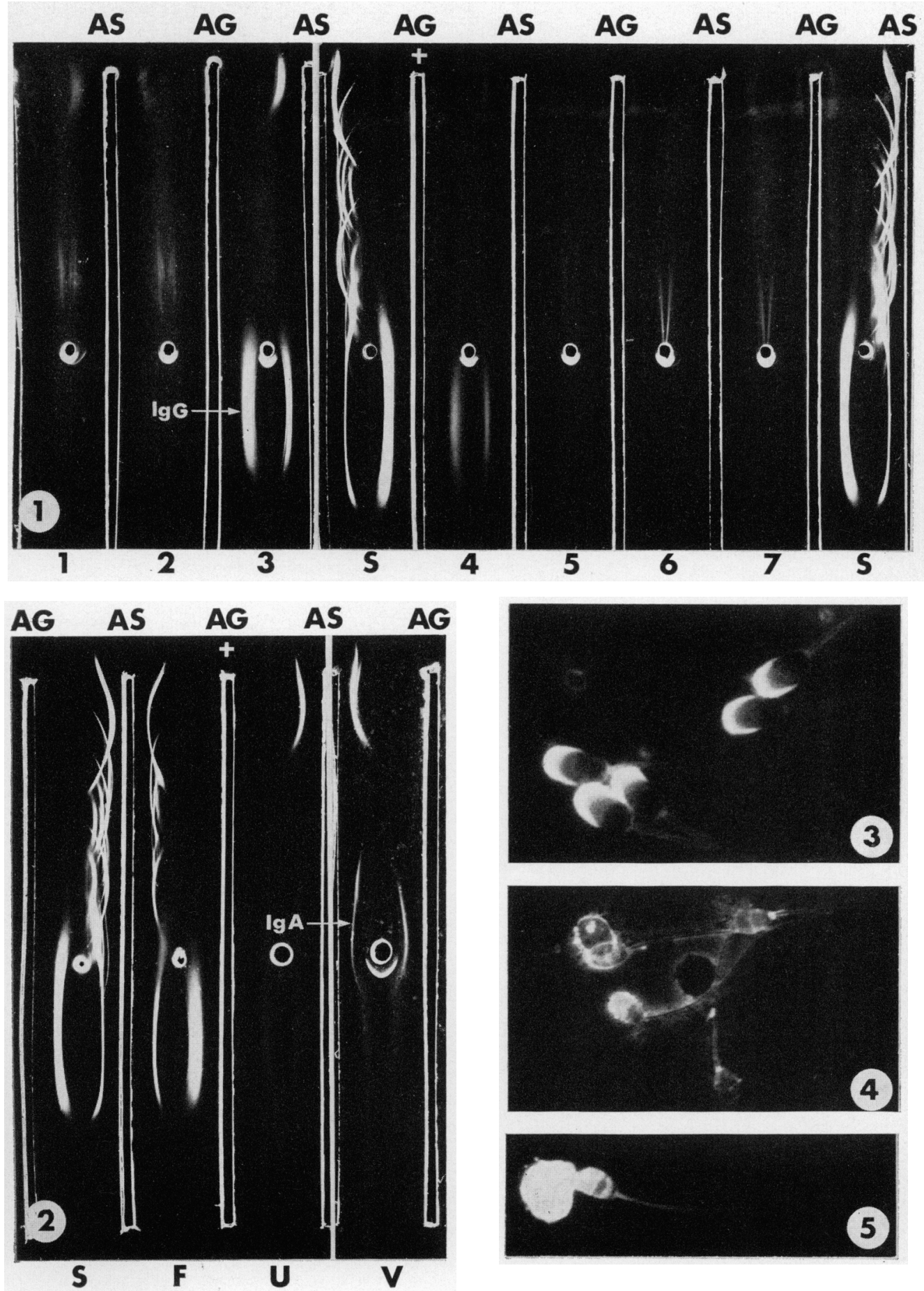
PLITE: 2
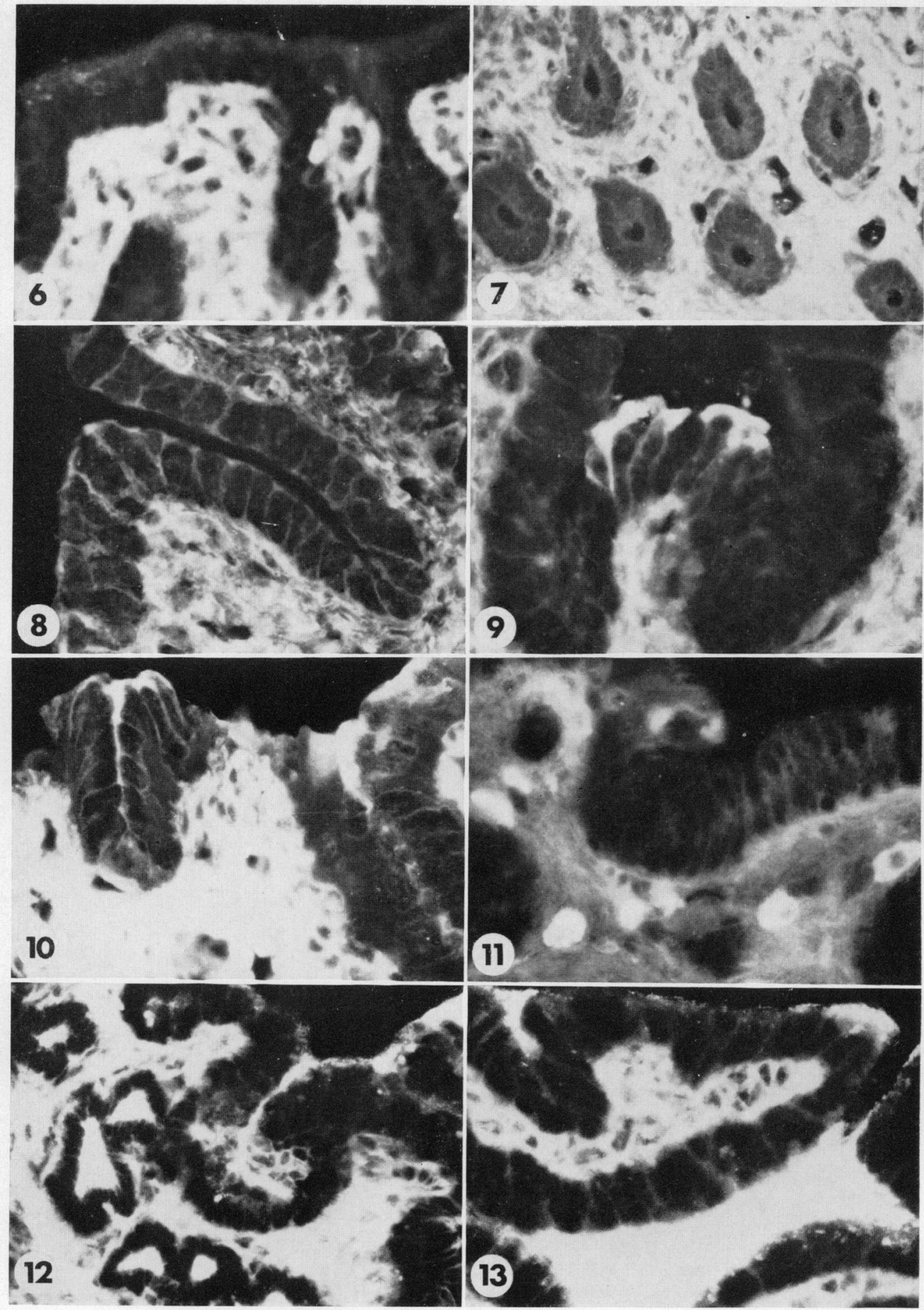
uterine fluid was very low. Vaginal fluid usually had a higher content of IgGglobulin than did uterine fluid, and in some instances a second immunoglobulin class, IgA, was present in vaginal fluid (Pl. 1, Fig. 2). Follicular fluid was comparable to serum in terms of its IgG concentration.

\section{Distribution of IgG-globulin in the tissues of the female genital tract}

The striking feature of the oestrous genital tract at all levels was the effectiveness of the barrier presented by the columnar epithelium to the free diffusion of IgG-globulin from tissue fluids into the lumen (Plate 2). IgG-globulin was widely and fairly evenly distributed, signified by bright fluorescence in all tissues, although its entry into the muscle tissue of the myometrium was often reduced. The cells of the columnar epithelium of the tract, however, were impermeable to this protein, as was shown by the complete absence of anti-IgG fluorescence in intracellular sites in the epithelium. Intercellular fluorescence of variable intensity was observed at all levels of the female tract (Plate 2), being most widespread in the vagina and less pronounced in the cervix and uterus respectively. Continuity of fluorescence from the basement membrane to the luminal aspect of the epithelium was prominent in the vagina (P1. 2, Figs. 10 and 11) and in small focal regions of the cervix (Pl. 2, Fig. 9).

\section{Pregnant uterus}

Uterus from a 14-day pregnant rabbit was intensely fluorescent for IgGglobulin in the lumina of uterine glands and their ducts. Intercellular fluorescence in the epithelium lining these structures was prominent (P1. 2, Figs. 12 and 13), whereas the epithelial cytoplasm was devoid of IgG. It was therefore concluded that, in the pregnant rabbit uterus, passage of IgG-globulin was also intercellular, but much more pronounced than in the oestrous uterus.

\section{DISCUSSION}

The problems of collecting uncontaminated or unmodified luminal fluids from the female genital tract have already been mentioned. The method applied in the present study resulted in the recovery of fluids which were entirely free from blood contaminants in most instances. Contamination with blood could

\section{EXPLANATION OF PLATE 2}

IgG immunofluorescence of female rabbit genital tract tissues.

Fig. 6. Uterus, $7 \mathrm{hr}$ p.c. Epithelium acts as barrier to diffusion of IgG into lumen $(\times 520)$. Fig. 7. Uterus, as above. Epithelium of uterine glands and ducts in transverse section show faint intercellular fluorescence $(\times 520)$.

FIG. 8. Cervix, $7 \mathrm{hr}$ p.c. Epithelium exhibits intercellular IgG $(\times 520)$.

Fig. 9. Cervix, as above. Local focus of increased intercellular IgG in epithelium $(\times 950)$.

FIG. 10. Vagina, $7 \mathrm{hr}$ p.c. Folds of epithelium with intercellular fluorescence and prominent accumulations of IgG in folds of epithelium $(\times 410)$.

Fig. 11. Vagina, as above. Cells of plasma series rich in IgG prominent in lamina propria $(\times 600)$.

FIGs. 12 and 13. Uterus, 14-day pregnant. IgG accumulation in lumina of glands and ducts. Intercellular distribution of IgG apparent in pregnant uterus $(\times 370$ and $\times 600)$. 
readily be detected by the presence of erythrocytes sedimented with spermatozoa and leucocytes after centrifugation. Very small amounts of contaminating blood could be detected in this way. Nevertheless, the problem of post mortem artifacts remains; significant changes in the uterine epithelium which occur very rapidly after death signify the sensitivity of this tissue to non-physiological conditions (Bartelmez, 1940). The samples of female fluids recovered in this study all contained IgG-globulin, together with IgA in vaginal fluid in some animals. A very similar electrophoretic pattern was obtained with the fluids from unmated oestrous rabbits, implying that these proteins were of maternal, not seminal, origin.

In contrast to the constant occurrence of IgG in the female genital fluids, this immunoglobulin class has been found to be very variable in seminal plasma even between ejaculates collected at short intervals from the same buck. In man, the equality of ratio between IgG and acid phosphatase in a series of seminal plasmas indicates that the prostate is the main source of IgG (Rümke, 1969). The random occurrence of IgG in the fluid portion of rabbit seminal plasma implies that it also is similarly secreted in the prostatic fluid, which makes a variable contribution to different ejaculates.

Reaction of rabbit globulin with spermatozoa recovered from the Fallopian tubes and uterus by retrograde washing has been previously described (Symons, 1967, 1968). The present results are in accord with the earlier studies, although two differences are noteworthy. Firstly, in the earlier experiments immunofluorescent tracing of globulins was employed, which was of wider spectrum than the present specific IgG-globulin tracing. Secondly, the possibility of contamination with plasma proteins could not be excluded in the earlier studies. It is probably because of these differences that the IgG-immunofluorescence of spermatozoa recovered from the female tract in the present study was weaker and confined to a smaller proportion of recovered spermatozoa than was observed in the earlier experiments. It is evident, however, that IgG-globulin in the luminal fluids had reacted with a proportion of the spermatozoa in the tract at $7 \mathrm{hr}$ p.c.

It has been calculated that 50 to $60 \%$ of the total body pool of IgG-globulin is extra-vascular (Cohen \& Porter, 1964), there being a dynamic equilibrium between intra- and extra-vascular plasma proteins. The present results reflect this state of affairs, immunofluorescence of IgG demonstrating a widespread incidence of this protein throughout the submucosal tissues of the female tract. In addition to the systemically derived IgG, there may be local high concentrations of IgG in close proximity to IgG-containing plasma cells, these cells frequently being seen in the lamina propria of the vagina and in decreasing numbers in the cervix and uterus.

The dominant feature observed at all levels of the female tract was the barrier to free diffusion of IgG-globulin from tissue fluid into the lumen of the tract presented by the epithelial layer. The effectiveness of this barrier appeared to decrease in a posterior direction, i.e. the vaginal epithelium was more permeable to IgG than was the uterine epithelium. This was reflected in the IgG concentrations in vaginal and uterine fluids, vaginal fluid containing generally more IgG-globulin than did uterine fluid. Permeability to immunoglobulin was 
apparent as intercellular immunofluorescence which was characteristic of the vaginal epithelium, present in small foci in the cervical epithelium and prominent in the pregnant uterus, particularly in the epithelium of uterine glands and ducts. No intracellular IgG was detected in the epithelium of any sample of female genital tract. Diffusion of IgG by an intercellular route is therefore suggested by the continuity of immunofluorescence between many cells, from the relatively high levels of IgG in the tissues to the low levels in the luminal fluids. Intercellular distribution of immunoglobulins has been similarly detected in nasal mucosa (Brandtzaeg, Fjellanger \& Gjeruldsen, 1967). It is not known if this type of transfer is selective; in pregnancy, both 7S-globulin and 19Smacroglobulin are transmitted across the rabbit uterus (Hemmings \& Jones, 1962), so there appears to be little selection on the basis of molecular size in pregnancy.

Ultrastructural studies have revealed the widespread incidence in different tissues of junctional complexes joining adjacent cells (Farquhar \& Palade, 1963). These complexes, in particular the zonula occludens, are assumed to circumvent each cell near the apex to form a 'tight junction' which is impermeable to large molecules. However, cell junctions are capable of dissociation, as, for example, when polymorphonuclear leucocytes traverse capillary endothelium by an intercellular route (Florey \& Grant, 1961; Marchesi, 1961). It is not known if the influx of polymorphs across the epithelium of the female genital tract causes a transient increase in epithelial permeability, or whether these cells enter through existing channels between adjacent cells.

A further factor which may influence the permeability of the genital tract epithelium is the enzyme hyaluronidase, introduced with spermatozoa at insemination. Hyaluronidase, first observed as 'spreading factor' by DuranReynals (1928), is known to cause an increased permeability of tissue due to its depolymerization and hydrolysis of the mucopolysaccharide cementing substance, hyaluronic acid. It is interesting that in the cervix, where focal areas of increased permeability to immunoglobulin were found, local concentrations of spermatozoa occurred in the tortuous folds of the epithelium (observed by conventional histological methods). Unfortunately, the freeze-drying method destroyed spermatozoa, thereby excluding the possibility of correlating local accumulations of spermatozoa with local increased epithelial permeability.

\section{ACKNOWLEDGMENTS}

We thank Dr P. J. Lachmann for providing details of the conjugation procedure. The assistance of Mr S. P. Mann and Mr L. G. Jarvis with the freezedried tissue preparations is gratefully acknowledged.

\section{REFERENCES}

Bartelmez, G. W. (1940) Some effects of fixation and other insults on uterine cpithelial cells in primates. Anat. Rec. 77, 509.

Beck, J. S., Edwards, R. G. \& Young, M. R. (1962) Immune fluorescence technique and the isoantigenicity of mammalian spermatozoa. F. Reprod. Fert. 4, 103.

BEIER, H. M. (1968) Biochemisch-entwicklungsphysiologische Untersuchungen am Proteinmilieu für die Blastozystenentwicklung des Kaninchens (Oryctolagus cuniculus). Zool. 7b. 85, 72.

BRAmbell, F. W. R. (1958) The passive immunity of the young mammal. Biol. Rev. 33, 488. 
Brandtzaeg, P., Fjellanger, I. \& Gjeruldsen, S. T. (1967) Localization of immunoglobulins in human nasal mucosa. Immunochemistry, 4, 57.

Conen, S. \& Porter, R. R. (1964) Structure and biological activity of immunoglobulins. Adv. Immunol. $4,287$.

DANIEL, J. C. (1968) Comparison of electrophoretic patterns of uterine fluid from rabbits and mammals having delayed implantation. Comp. Biochem. Physiol. 24, 297.

Duran-Reynals, F. (1928) Exaltation de l'activité du virus vaccinal par les extraits de certains organes. C.r. Séanc. Soc. Biol. 99, 6.

EdWARDs, R. G. (1960) Complement-fixing activity of normal rabbit serum with rabbit spermatozoa and seminal plasma. F. Reprod. Fert. 1, 268.

EDWARDs, R. G. (1969) Transmission of antibodies across membranes of the reproductive tracts. In: Immunology and Reproduction. Ed. R. G. Edwards. International Planned Parenthood Federation, London.

FarQuhar, M. G. \& Palade G. E. (1963) Junctional complexes in various epithelia. F. Cell Biol. 17, 375.

Florey, H. W. \& GRANT, L. H. (1961) Leucocyte migration from small blood vessels stimulated with ultraviolet light: an electron microscope study. 7. Path. Bact. 82, 13.

HeAP, R. B. (1962) Some chemical constituents of uterine washings-a method of analysis with results from various species. F. Endocr. 24, 367.

Hemmincs, W. A. \& Jones, R. E. (1962) The occurrence of macroglobulin antibodies in maternal and foetal sera of rabbits as determined by gradient centrifugation. Proc. $R$. Soc. B, 157, 27.

Johnson, M. H. (1968) The characterization of a natural antibody in normal guinea-pig serum reacting with homologous spermatozoa. F. Reprod. Fert. 16, 503.

MarchesI, V. T. (1961) The site of leucocyte emigration during inflammation. Q.Fl exp. Physiol. 46, 115.

NAIRN, R. G. (1962) Fluorescent protein tracing. Ed. R. G. Nairn. Livingstone, Edinburgh.

O'Donnelt, J. M. \& Symons, D. B. A. (1970) Centrifugal patterns and morphological variation of bull spermatozoa. F. Reprod. Fert. 23, 41 .

Pierce, A. E. \& Feinstein, A. (1965) Biophysical and immunological studies on bovine immune globulins with evidence for selective transport within the mammary gland from maternal plasma to colostrum. Immunology, 8, 106.

Porter, R. R. (1959) The hydrolysis of rabbit $y$-globulin and antibodies with crystalline papain. Biochem. F. 73, 119.

RüMKE, P. (1969) Clinical aspects of autoimmunity to spermatozoa in men. In: Immunology and Reproduction. Ed. R. G. Edwards. International Planned Parenthood Federation, London.

Schemegger, J. J. (1955) Une micro-méthode de l'immunoélectrophorèse. Int. Archs Allergy appl. Immun. 7, 103.

SPOONER, R. L. (1964) Cytolytic activity of the serum of normal male guinea pigs against their own testicular cells. Nature, Lond. 202, 915.

Stevens, K. R., HAFs, H. D. \& Hunter, A. G. (1964) Immunochemical and electrophoretic properties of oestrous rabbit uterine fluid proteins obtained by uterine ligation. 7. Reprod. Fert. 8, 319 .

Symons, D. B. A. (1967) Reaction of spermatozoa with uterine and serum globulin determined by immunofluorescence. F. Reprod. Fert. 14, 163.

Sxmons, D. B. A. (1968) Immunoftuorescent study of the antigenicity of mammalian spermatozoa, Ph.D. thesis, University of London. 